\title{
O hexÂmetro datílico de Carlos Alberto NUNES: TEORIA E REPERCUSSÕES
}

\section{Carlos Alberto Nunes' dactylic hexameter: theory and effects}

\author{
João Angelo Oliva Neto*
}

\begin{abstract}
RESUMO
O artigo visa a aprofundar o estudo sobre hexâmetro datílico vernáculo de Carlos Alberto Nunes, observando 1) a exígua teoria do hexâmetro datílico português que Nunes deixou, em particular sobre a não-substituição de pés e sobre os tipos de cesura: a prática de Nunes é mais ampla que a teoria; e 2) as repercussões que as traduções de Nunes tiveram em tradutores contemporâneos e até mesmo na poesia original composta em português.
\end{abstract}

Palavras-chave: Carlos Alberto Nunes; hexâmetro datílico; tradução poética hexamétrica.

* Universidade de São Paulo. 


\begin{abstract}
This paper aims to extend investigations about Carlos Alberto Nunes' Portuguese dactylic hexameter. The main concern now is 1) the brief theorization Nunes left about his own practice, particularly about his absolute avoidance to substitute trochees for dactyls and his way of making caesura: it can be seen Nunes practice is far wider than his theory; 2) the effect his translations had in present translators and even in original poetry composed in Brazil.
\end{abstract}

Keywords: Carlos Alberto Nunes; dactylic hexameter; poetic hexametrical traslation.

\title{
1. A nova tendÊNCIA DE TRAduções heXamÉtricas na EuRopa
}

Em anos bem recentes, observa-se na Europa e nos Estados Unidos um fenômeno na tradução da épica antiga, e para dizer a verdade, principalmente da homérica, que é a reutilização do hexâmetro datílico em língua moderna. Com efeito, sempre hexamétricas, na Espanha, Agustín García Calvo, que faleceu em 2012, publicou tradução da Ilíada em 1995; nos Estados Unidos, Rodney Merrill, da Odisseia em 2002 e da Ilíada em 2007; na França, Philippe Brunet da Odisseia em 2003 e da Ilíada em 2010; na Itália Daniele Ventre, da Ilíada em 2010, e na Romênia, George Murnu (1868-1957) traduziu a Ilíada e a Odisseia (1956) e assim como Dan Slusanschi (1943-2008), ao que parece na primeira década deste século. Dizer "reutilização" deve-se ao fato de que o hexâmetro datílico já tinha sido utilizado por mais que centenária linhagem de poetas italianos, que com Leonardo Dati (1360-1425?) e Leon Battista Alberti (1404-1472) ${ }^{1}$ foram os primeiros a cunhá-lo em língua moderna. Os dois, participando em 1441 de uma contenda poética sobre o tema da amizade, compuseram poemas

1 A eles seguiram-se os italianos Ludovico Ariosto (1474-1533), Bernardo Tasso (1493-1569), Gabriello Chiabrera (1552-1638), Niccolò Tommaseo (1802-1874), Claudio Tolomei (1492-1556), Anibale Caro (1507-1566), Antonio Minturno (1500-1574), Giosué Carducci (18351907), Giovanni Pascoli (1855-1912), Enrico Thovez (1869 -1925), Ettore Romagnoli (1871-1938); ver Giosuè Carducci, La Poesia Barbara nei Secoli XV e XVI. 
hexamétricos. Seguiram-se outros italianos, e também alemães ${ }^{2}$, ingleses ${ }^{3}$ (e americanos), espanhóis (e hispano-americanos) ${ }^{4}$, franceses, russos. Deste vasto conjunto, que se poderia talvez chamar "epígonos", dois grupos se destacam por causa da discussão teórica e técnica que protagonizaram acerca do modo de aclimatar modernamente o hexâmetro: o primeiro reúne, entre o fim do século XVIII e o começo do XIX, os alemães Friedrich Gottlieb Klopstock (1724-1803) e Heinrich Voss (1751-1826), os quais, discordando quanto às cesuras relativas ao sentido do verso, produziram modalidades diferentes de hexâmetro nessa língua. Em breves termos, Klopstock fazia quase sempre coincidir as pausas das cesuras com o conteúdo dos versos, ao passo que Voss, imitando mais de perto os antigos, não produzia a coincidência ${ }^{5}$. 0 segundo grupo, cem anos depois, entre o fim do século XIX e o início XX, reúne os italianos Giosuè Carducci, com as Odi barbare, publicadas entre 1877 e 1889 , e seu discípulo Giovani Pascoli, que, além de praticar metros antigos, os teorizou em "Regole di metrica neoclassica" 6 . Em meio a inúmeros poetas das línguas europeias, uns pouquíssimos portugueses e apenas um brasileiro praticaram o hexâmetro datílico antes de Carlos Alberto Nunes. Apenas arrolo-os, a eles e aos poemas hexamétricos.

1) José Anastácio da Cunha (1744-1787), que em hexâmetros escreveu:

a) Idílio "Menalca e Tírsis, de Gessner"7, cujo original é em prosa;

b) excerto final do livro 2 das Geórgicas, de Virgílio.

2 Em hexâmetros, Friedrich Gottlieb Klopstock publicou $O$ messias em 1748; Heinrich Voss traduziu a Odisseia em 1781, a Ilíada em 1793, passagens de Ovídio (1798), todo Virgílio em 1799; compôs o idílio Luise em 1795; Goethe (1749-1832) compôs o idílio Hermann und Dorothea ("Hermann e Doroteia", 1797). O hexâmetro formando dístico com pentâmetro o próprio Goethe (1749-1832) empregou nas Romische Elegien ("Elegias romanas", 1790), assim como também Schiller, Holderlin e outros mais. No século XIX Morike utilizou hexâmetro no Idylle vom Bodensee ("Idílio do Lago de Constance", 1846); Hebbel no idílio épico Mutter und Kind ("Mãe e filho", 1859); no século XX, Thomas Mann no poema Gesang vom Kindchen ("Canção da criancinha", 1919) e Brecht no poema inacabado Das Manifest ("O manifesto", 1945). O suíço Johann Jakob Bodmer imitou Klopstock para escrever Noachide (1752-1765), epopeia sobre o Dilúvio e outras epopeias bíblicas e mesmo tragédias em hexâmetros. Assim verteu a Ilíada e a Odisseia, ao que parece do latim, e as Argonautica de Apolônio de Rodes.

3 A linhagem anglófona: Samuel Taylor Coleridge (1771-1834); Robert Southey (1774-1843); Henry Wadsworth Longfellow (1807-1882); Arthur Hugh Clough (1819-1861).

4 Para a longuíssima linhagem em língua espanhola, ver Francisco Pejenaute (1971), "La adaptación de los metros clasicos em castellano".

5 "O hexâmetro requer múltiplas variações de ritmo, e o domínio da consonância por si mesmos, independentemente do assunto. Que ambos, tanto quanto possível, devam marcar a expressão do pensamento, é uma lei que em tudo e por tudo o grande poeta segue: mas que, mal compreendida, também conduz ao erro. Muitos pensamentos não são passíveis de expressão métrica [...].” Tradução do professor Érico Nogueira, cuja fidalguia aqui agradeço.

6 In Poesie e prose scelte. Tomo secondo. Milano: Arnoldo Mondadori Editore, 2002.

7 Salomon Gessner (1730-1788), escritor, tradutor, pintor e gravador suíço, notório pela matéria pastoral. 
2) Vicente Pedro Nolasco da Cunha (1773-1844):
a) "Ao exmo conde de Palmela. Epístola hexamétrica";
b) "O Incêndio de Moscou";
c) "Epicédio a uma noiva";
d) "Brasiliae Principi".

3) José Maria da Costa e Silva ("Elpino Tagídio", 1788-1854):

a) "Epicédio à morte do elegante poeta dramático Antônio Xavier Ferreira de Azevedo";

b) "Epístola ao doutor Vicente Pedro Nolasco da Cunha".

4) Júlio de Castilho (1840-1919, filho de Antônio Feliciano):

a) pequeno excerto hexamétrico parafreseando passagem do canto IV da Eneida;

b) pequeno excerto elegíaco, parafreseando a mesma passagem do canto IV da Eneida.

5) Carlos Magalhães de Azeredo, brasileiro (1872-1963), cujos hexâmetros ocorrem em dísticos elegíacos no livro Odes e elegias, publicado em 1904.

6) Fernando Pessoa (1888-1935) deixou registrados em manuscrito só recentemente transcrito e publicado excertos hexamétricos que são traduções de Horácio (Arte poética, v. 1-8), Virgílio (Eneida I, 1-8; outra versão dos versos I, 3-4; uma tradução livre de versos soltos do canto IV, 180-181; uma tradução livre de versos soltos do canto VI, 254-272); Geórgicas (IV, 1-2).

7) Carlos Alberto Nunes, que nessa linhagem vernácula, até onde sabemos, é o próximo, e mais exatamente o sétimo hexametricista lusófono: em hexâmetros publicou na década de 1940 a tradução da Ilíada e da Odisseia e muito depois, em 1981, já idoso, a da Eneida, cuja republicação tivemos o privilégio de organizar. Assim realizadas, estas ainda são as primeiras e únicas traduções completas em língua portuguesa das epopeias homéricas e da virgiliana. Ademais, por um curioso acaso, as datas em que Nunes as publicou, não obstante o interregno de quase 40 anos entre as duas primeiras e a terceira, colocam-no numa posição extraordinária, pois, em confronto com predecessores europeus, mesmo os mais recentes no século XIX, pode-se dizer que suas versões completas são de fato tardias: vá lá, quae sera, tamen. Entretanto, publicadas que foram na década de 1940 e, no caso da Eneida, em 1981, se confrontadas agora com a nova 
tendência hexamétrica de traduzir épica clássica, as traduções brasileiras de Nunes estão 50 anos a frente deles! Veremos adiante que a linhagem, por causa dele, não termina com ele.

\section{NUNES: INCANSÁVEL TRADUTOR}

Carlos Alberto da Costa Nunes nasceu em São Luís do Maranhão, em 19 de janeiro de 1897, e formou-se médico em 1920 pela Faculdade de Medicina da Bahia, exercendo a profissão em cidades do interior paulista até fixar-se na capital, onde trabalhou como médico-legista. Compôs em decassílabos a epopeia Os Brasileidas (1938), os dramas Moema (1950), Estácio (1971) e Beckmann ou a tragédia do general Gomes Freire de Andrade em cinco atos e um prólogo (1975); a comédia Adamastor ou o naufrágio de Sepúlveda (1972). Do alemão traduziu as tragédias Estela (1949) e Ifigênia em Táuride (1964) de Goethe, e de Friedrich Hebbel, Judite, Giges e seu anel, e Os nibelungos (1964, todas num só volume). Do espanhol traduziu A Amazônia: tragiepopeia em 4 jornadas, do uruguaio Edgardo Ubaldo Genta (1968). Traduziu o teatro completo de Shakespeare, publicado em 21 volumes (1955). Do grego traduziu todos os Diálogos de Platão, publicados em catorze volumes entre 1973 e 1980, a Odisseia (1941) e a Ilíada (após $1945)^{8}$. Do latim traduziu a Eneida, publicada em 1981, bimilenário da morte de Virgílio, uma das poucas traduções hexamétricas do poema ${ }^{9}$. A partir de 1956 foi membro da Academia Paulista de Letras. Era tio do filósofo, poeta e ensaísta Benedito Nunes (1929-2011), e faleceu em Sorocaba em 9 de outubro de 1990. A avaliação crítica e histórica de sua vasta obra, original e traduzida, está ainda por fazer. Tratarei aqui apenas de seu hexâmetro datílico.

8 Muito tenho pelejado para determinar a data da primeira edição da Ilíada e a da Odisseia, de Carlos Alberto Nunes: na edição sem data da Ilíada da editora Atena diz o tradutor em "Nota" (p. 445): "Esta tradução da Ilíada foi escrita de acordo com a reforma ortográfica luso-brasileira consubstanciada nas normas do Vocabulário da Academia das Ciências de Lisboa. [...] Eis por que se corrigiram, agora, alguns nomes que figuram com diferente grafia na tradução da Odisseia, publicada em 1941, nesta mesma coleção, e que, para uniformidade dos textos, serão também alterados nas edições subsequentes daquela obra". Estabelece-se, assim, o ano de 1941 para a primeira edição da Odisseia. A "reforma" a que se refere Carlos Alberto Nunes deve ser o Acordo Ortográfico de 1945, convenção ortográfica assinada em Lisboa em 6 de outubro daquele ano entre a Academia das Ciências de Lisboa e a Academia Brasileira de Letras, e não o Formulário Ortográfico de 1943, da Academia Brasileira de Letras, que fundamentou seu Vocabulário ortográfico. O acordo de 1945 não foi ratificado pelo Congresso brasileiro, o que parece explicar que Carlos Alberto mencione o Vocabulário Ortográfico da Academia das Ciências de Lisboa.

9 São hexamétricas as traduções em inglês Virgil's Aeneid: translated literally, line by line, into English dactylic hexameter by Oliver Crane (1888), Cornell University Library, 2009, e a de Frederick Ahl, Vergil, Aeneid. Introduction by Elaine Fanthan. Oxford: University Press, 2007. 
A Ilíada e a Odisseia de Carlos Alberto Nunes foram as únicas traduções poéticas integrais em português de Homero feitas e publicadas no século XX no Brasil e até muito recentemente eram ainda as últimas, até Haroldo de Campos publicar a tradução integral da Ilíada (2002), Donaldo Schüler e Trajano Viera, a da Odisseia (2007 e 2011), e, em Portugal, Frederico Lourenço publicar ambas (2005 e 2003). Na linhagem de traduções das epopeias gregas e latinas em nossa língua o que singulariza as de Nunes é precisamente o metro utilizado. A singular proposta de traduzir a épica grega e a romana em hexâmetros datílicos portugueses deveria ter merecido desde a primeira hora maior atenção no Brasil - senão, por assim dizer, nos "meios literários", onde pelo menos foi mencionada, - ao menos na Universidade brasileira, sobretudo a partir dos anos de 1960, quando tradução passou a ser teoricamente encarecida. Não mereceu até agora. É o momento, pois, de refletir sobre essa modalidade particular de tradução e, oxalá, contribuir para acumular conhecimento sobre ela e para o que um dia há de ser a história da tradução poética da poesia antiga em português. Quanto a Eneida, não fosse a tradução do luso-brasileiro Agostinho da Silva, do início dos anos $90^{10}$, seria de Carlos Alberto a última tradução poética vernácula integral do poema de Virgílio publicada ${ }^{11}$. Estas são virtudes extrínsecas, mas na série de traduções das epopeias gregas e latinas só as de Nunes são hexamétricas, e ele mesmo ou os primeiros editores fizeram praça disso: com efeito, as edições iniciais da Ilíada e da Odisseia vertidas por Nunes, que datam da década de 40 (Athena Editora), trazem na capa os dizeres "traduzidas do grego, no metro original por Carlos Alberto Nunes", diferentemente do que ocorreria nas reedições subsequentes, como a da Editora Tecnoprint na década de 1980, que ao menos anunciam ser "em verso(s)", e da Ediouro na década de 2000, que nem isso faz), $O$ encarecimento do hexâmetro também ocorre na Eneida, de 1981: "Tradução portuguesa de Carlos Alberto Nunes no metro original". É muito provavelmente do tradutor a valorização da escolha métrica logo na página de rosto, destacando o conceito de que seria o "metro original". A bem dizer, o hexâmetro datílico português de Carlos Alberto Nunes, consiste em simular (ou "interpretar" como ele diz) o dátilo substituindo-se a sílaba longa por uma sílaba tônica e as duas sílabas breves por duas átonas. Conforme se considere, se se supuser a existência de ictos - que aqui não discuto - deve-se dizer então que a simulação do dátilo consiste na manutenção dos seis ictos fazendo-se neles incidir a sílaba

10 Pela informação deixo lavrado meu agradecimento ao Professor Amon Santos Pinho, da Universidade Federal de Uberlândia, grande conhecedor da obra filosófica de Agostinho da Silva.

11 Será publicada ainda este ano pela Editora Autêntica (MG) a tradução poética da Eneida realizada pelo professor João Carlos Mota. A versão, como afirma o tradutor, é isossilábica, cada verso mantendo o mesmo número de sílabas do respectivo verso latino. 
tônica das palavras, reservando-se as átonas para as sílabas breves. Para leitores não especialistas em letras antigas exemplifico com versos iniciais da Ilíada, marcando as sílabas tônicas e as cesuras:

\author{
Canta-me a cólera - ó deusa // - funesta de Aquiles Pelida, \\ causa que foi de os Aquivos // sofrerem trabalhos sem conta \\ e de baixarem para o Hades // as almas de heróis numerosos \\ e esclarecidos//, fican//do eles próprios// aos cães atirados \\ e como pasto das aves. // Cumpriu-se de Zeus o desígnio
} desde o princípio em que os dois // em discórdia ficaram cindidos:

\title{
3. A teoria do hexâmetro de Carlos Alberto Nunes
}

Nunes fala muito pouco sobre o próprio hexâmetro e, quando fala, não nomeia os precursores portugueses, nem, aliás, os estrangeiros. Mas não deixa de fazer-lhes menção (Nunes, 1962, p. 38-89):

No caso de Homero essa atitude [i. e. distanciar-se objetivamente dos fatos narrados] encontrou meio felicíssimo de expressão na medida exclusiva da epopeia grega, o hexâmetro, que iria impor-se, depois, na literatura latina e, em parte, nas modernas, como o verso mais adequado para esse genero de poesia. Firmemos, portanto, mais uma característica do estilo épico: a uniformidade do verso. "Homero emerge da corrente da vida", diz Staiger, "e se conserva imóvel em face do mundo exterior; contempla as coisas de um certo ponto de vista, por uma determinada perspectiva. Esta é condicionada pelo ritmo de seus versos, sendo ela que lhe assegura a identidade, o ponto fixo no fluxo permanente das coisas". É essa condição que permite ao poeta conservar a serenidade em face dos acontecimentos relatados. Interpretando o hexâmetro em termos da métrica portuguesa, veremos que se trata de um verso longo, de dezesseis sílabas, paroxítono, com acento predominante na $1^{\underline{a},} 4^{\mathrm{a}}, 7^{\mathrm{a}}, 10^{\mathrm{a}}, 13^{\mathrm{a}}$ e $16^{\underline{a} \mathrm{a}}$ sílabas e discreta cesura depois do terceiro pé:

Ouve-me, Atena, também, // nobre filha de Zeus poderoso!

Quando o poeta se afasta desse paradigma, para introduzir duas pausas no verso, que o dividem em três porções quase iguais, de regra volta no verso subsequente a cair no ritmo inicial, que é o predominante em todo o recitativo:

Dá que possamos / cobertos de glória / voltar para as naves, pós grande feito acabarmos / que há de lembrar sempre aos Teucros!

Nas traduções esse esquema não é observado com rigor, notando-se, 
ainda, a tendência para variar de ritmo, pelo deslocamento das pausas dentro do verso, com o que se evita a monotonia, de possível desagrado para o ouvido moderno. Mas com isso padece o estilo épico em uma de suas características essenciais.

Breve que seja o passo, Nunes nos dá, porém, preciosas informações. A primeira é que conhece composições hexamétricas modernas: "o hexâmetro, que iria impor-se, depois, na literatura latina e, em parte, nas modernas". Não se sabe de quais línguas e de quantas, nem se incluem os poetas portugueses. Informa também características do seu hexâmetro, que, sem respeitar a ordem, são as seguintes:

1) Não admite substituições. Nunes não diz assim, mas implica-o quando aponta que o verso tem 16 sílabas métricas. A leitura de suas traduções no-lo demonstram, mas se por acidente não dispuséssemos delas e se ele, em vez de mencionar as 16 sílabas, apenas indicasse haver seis sílabas tônicas jamais seguidas de mais de duas átonas, que arruinariam o andamento datílico, não saberíamos se acolhia ou não acolhia as substituições. Não explica, todavia, por que não acolhe a mudança do dátilo pelo que é na verdade um troqueu vernáculo, ao contrário dos hexametricistas antigos, portugueses inclusive, que assim procedem. Só se pode inferir que ele, assumindo como absoluta a inexistência de quantidades em português, não tenha aceitado substituir o dátilo originário e essencial por um pé que, formado de uma tônica e uma átona, é na verdade um troqueu, e não um espondeu, como ocorre no hexâmetro antigo. Inferindo mais a fundo, parece não lhe ter bastado os seis ictos, mesmo não seguidos de mais de duas átonas, para forjar "o metro original", como diz mais de uma vez, mas sim a estrita recorrência das seis tônicas seguidas de duas átonas, exceto no último pé.

2) O hexâmetro que Nunes pratica tem sempre uma cesura, como vimos, maiormente pentemímera, ou uma trimímera e outra heptemímera, que é excepcional, como admite. Não se sabe se com a locução "nas traduções" está a referir-se apenas a suas traduções, ou se a elas inclusive, ou se só às alheias, mas deixa claro que é desvio não ater-se à predominância da cesura pentemímera que observa em Homero. Porém importa o outro desvio que observa "nas traduções", que consiste em deslocar as pausas no verso para evitar monotonia desagradável ao ouvido moderno. Aqui, a frase "notando-se, ainda, a tendência" não parece dizer respeito às próprias traduções, mas antes revelar crítica quanto às alheias, tanto mais que respeitar o ritmo e as pausas é uma das "características essenciais" do "estilo épico". Com efeito, o exame dos versos hexamétricos de Nunes mostra ausência quase absoluta de deslocamento das pausas. A teorização é mesmo exígua, porque a bem dizer Nunes não detalha no interior de cada cesura as possibilidades feminina e masculina, que ele de fato pratica. Dos dois exemplos que deu, no primeiro a 
cesura pentemímera é masculina (nos tratados de métrica também chamada "oxítona" ou "aguda" ou "no tempo"), pois o corte incide na última sílaba de "também". Vejamos, só por contrastar e detalhar melhor a prática de Nunes, um exemplo (Ilíada, II, 1) da mesma cesura pentemímera, porém feminina (nos tratados de métrica também chamada "paroxítona" ou "grave" ou no "contratempo"):

Os outros deuses e os homens, // que em carros combatem, dormiam.

Aqui o corte incide após a palavra "homens", mas a tônica não incide na última sílaba da palavra e do hemistíquio -mens, que é átona. Ainda que sem estatística acurada, percebe-se ser esta cesura - pentemímera, como o próprio Nunes diz - a mais comum do tradutor. Veja-se agora exemplo de cesura trimímera masculina em pelo menos um dos dois primeiros terços do verso, no caso o segundo (Ilíada, II, 2):

a noite toda. // Somente Zeus pai // não gozava do sono.

O acento e o corte incidem na mesma sílaba do monossílabo "pai" do segundo terço do verso.

3) A cesura, tal como ele a entende, não supõe apenas o acento e o corte no final de uma palavra nos locais devidos segundo as possibilidades que acabamos de mostrar. Supõe ademais que a pausa do hemistíquio ou do terço do verso coincida, segundo o que ali se enuncia, ou com a pausa semântica ou com a mudança de tom de voz, bem entendido, aquilo que os anglófonos chamam pitch. Em outras palavras, guarda relação com os grupos sintático-semânticos do verso. No primeiro exemplo de Nunes, a cesura no fim de "também" coincide com a pausa, propriamente dita, necessária ao aposto que se segue, "nobre filha de Zeus poderoso", referente a "Atena". No segundo exemplo, as duas cesuras após "possamos" e "glória", correspondem à mudança de tom da voz devida ao predicativo do sujeito "cobertos de glória", intercalado entre os verbos da locução verbal "possamos voltar". Não seria a rigor pausa temporal, um pequeno silêncio, mas elevação do tom de voz, que não deixa de indicar algum fenômeno sintático-semântico ${ }^{12}$. Assim sendo, não é um bom hexâmetro à maneira de Nunes o que apenas contém as 16 sílabas e apresenta os acentos nos devidos lugares, se não apresentar

12 Apenas para esclarecer a mudança no tom da voz, lembro que é o que ocorre entre uma oração subordinada adjetiva explicativa e sua principal. Não há pausa temporal, mas só abaixamento no tom de voz. Entre uma oração subordinada adjetiva restritiva não há nem pausa nem mudança no tom de voz. 
cesura segundo uma das duas possibilidades que ele descreveu, como este de minha parca autoria:

deve tolher // alentando a magní//fica Ilíaca luta ${ }^{13}$.

Se supusermos, como creio, que o gerúndio "alentando" impõe pausa semântica após "deve tolher” por iniciar a nova oração, a cesura, que é trimímera, ali é bem feita. Esta cesura trimímera, conforme o segundo modelo de Nunes, impõe que haja a cesura heptemímera, cujo corte deveria ocorrer ou logo após a própria sílaba acentuada -ní de "magnífica", se a cesura fosse masculina, ou logo após a sílaba átona - fi da mesma palavra, se a cesura fosse feminina. Entretanto, como se vê, a palavra "magnífica" não termina nem na sílaba -ni nem na sílaba $-f i$. Este não é um verso à maneira de Nunes.

4) Por conseguinte, Carlos Alberto Nunes, no que tange à relação entre cesura e conteúdo sintático-semântico do verso, parece adotar a doutrina de Klopstock. Não se pode afirmar com certeza porque infelizmente ele não o patenteia, mas é bem verossímil a possibilidade dado que Nunes foi também tradutor do alemão. Se assim for, poderíamos conjecturar que a passagem "pelo deslocamento das pausas dentro do verso" se refira à doutrina de Voss, oposta à de Klopstock, que Nunes então seguiria, ou seja, seria concernente à não-coincidência entre as cesuras e o conteúdo sintático-semântico do verso.

As considerações de Nunes acerca do hexâmetro enfim respondem melhor a uma dúvida que costuma ocorrer aos leitores das suas versões, a saber, por que, ao compor o poema épico Os Brasileidas, ele não usou o hexâmetro datílico? A resposta, creio, é o distanciamento objetivo que ele crê que Homero tenha dos fatos narrados, com o corolário de que o poeta então conserva a serenidade em face dos acontecimentos narrados, o que prenuncia (o texto de Nunes é ensaio introdutório ao poema) que esta não é a perspectiva do poeta n'Os Brasileidas. Compostos em decassílabos brancos e celebrando o bandeirante Raposo Tavares, o poema foi publicado em 1938 , data que o insere na tendência nacionalista, "Pau-Brasil" ou "Verde-Amarelo", da poesia brasileira do período. Nacionalista ou mesmo conservadora que seja a vertente ideológica do poema, é certo, justamente por isso, que não existem nem distanciamento nem serenidade do poeta em face dos acontecimentos narrados, mas vera adesão: 
Sobe imaginação! Abre os arcanos das lendas ameríndias, e dos Andes me facilita os penetrais augustos. Deixa ficar meu verso como o rio das famosas guerreiras, quando as águas aos tálamos da luz solene guia: caudal e majestoso. Não menores imagens me concede, altos remígios aos feitos adequados, porque eu canto do Brasil a excelência, na aristia do férreo bandeirante celebrada.

(Os Brasileidas, I, 15-25)

Se o título do poema de Nunes sabe a Os Lusíadas, o mesmo não ocorre com a ausência de estrofes e rimas, que tem na épica lusófona antecedentes como o Uraguai, de Basílio da Gama, A Conferederação dos tamoios, de Gonçalves de Magalhães ${ }^{14}$ e Os timbiras, de Gonçalves Dias.

\section{A cRítica (MUITO) PARCA}

Um dos poucos críticos a comentar as traduções de Nunes foi Haroldo de Campos. Num importante artigo de 1992, comentou-o para apontar-lhe defeitos, o que em si não é problema:

No que respeita à tradução de Carlos Alberto Nunes, embora não se possa enquadrar na categoria da "transcriação" (termo que é lícito aplicar, sem exagero, a Odorico [Mendes], não obstante os eventuais "desníveis" que possam afetar o resultado estético de seu projeto tradutório), estamos diante de uma empreitada incomum, que merece, como tal, respeito e admiração. Desde logo pelo fôlego do tradutor, que levou a cabo a transposição integral, em versos, para o português, de ambos os extensos poemas [Ilíada e Odisseia]. Num outro plano, o prosódico, pela interessante solução (louvada por Mário Faustino, se bem me lembro) de buscar num

14 Sobre a inconveniência de rima no poema épico escreve o poeta: "A repetição dos mesmos sons, que dá graça em certos lugares, é ridícula em outros e, prolongada, torna-se insuportável e soporífica, como o seria a música que não variasse de compasso e de notas; e jamais compensa em um poema heroico o dano que causa à energia do estilo, à gravidade do pensamento, à variedade das pausas, à naturalidade da linguagem, à viveza do diálogo, à liberdade na escolha da expressão, e à mais conveniente colocação das palavras, o que tudo se sacrifica à monotonia da rima e à simetria das estâncias, que não dão beleza alguma”. In TEIXEIRA, p. 854. 
verso de dezesseis sílabas o equivalente, em métrica vernácula, do hexâmetro (verso de seis pés) homérico. O resultado, para o nosso ouvido, embora relente um pouco o passo do verso, aproximando-o da prosa ritmada, é uma boa demonstração de que não assistia razão a Mattoso Câmara Jr., quando impugnava a aclimatação do verso de medida longa em português, considerando-o "inteiramente anômalo" em nossa língua (Mattoso referia-se à adoção de um verso de quinze sílabas por Fernando Pessoa, em sua tradução de The Raven, de E. A. Poe) ${ }^{15}$. A prática de Carlos Alberto Nunes, sustentando com brio, por centenas de versos, essa medida, contesta eloquentemente aquela restrição normativa. No que se refere à linguagem, todavia, não é um empreendimento voltado para soluções novas, com a estampa da modernidade. Trata-se, antes, de uma tradução acadêmica, de pendor "classicizante", que retroage estilisticamente no tempo.

O que é problemático, mormente em quem desfruta de tanto prestígio no Brasil no que toca à tradução, foi apontar-lhe defeitos que não tem: lentidão e prosaísmo. Tal juízo indica desconhecimento das muitas discussões sobre esse metro em vários países, porque não lhe dá a leitura que ele reclama. o prosaísmo não está no metro, mas na leitura dele. O verso será de fato prosaico e monótono se for lido à martelada, sem cesura. A cesura no hexâmetro datílico português divide-o em hemistíquios ou terços que são, eles mesmos, metros bem conhecidos na tradição poética lusófona. Vejamos este (Eneida, I, 11):

Cabe tão fero rancor // no' imo peito dos deuses eternos?

A cesura pentemímera divide o verso em duas partes. Mas o fato mesmo de que ela existe não foi notado por Haroldo de Campos nem de resto pelos poucos comentadores lusófonos que trataram do hexâmetro, de modo que não se percebeu tampouco outro efeito importante que ela produz. Lida corretamente, a cesura divide aqui o hexâmetro datílico em duas partes, das quais a primeira é um comuníssimo verso de sete sílabas:

Cabe tão fero rancor,

e a segunda é um de nove sílabas:

no' imo peito dos deuses eternos? 
O mesmo ocorre com as cesuras tri e heptemímeras (Eneida, I, 71):

No meu cortejo // se encontram quatorze // belíssimas ninfas.

O efeito agora é uma sequência de outros ritmos igualmente familiares; um verso de quatro sílabas:

No meu cortejo;

Seguido de dois versos de cinco sílabas:

se encontram quatorze

belíssimas ninfas.

A cesura, quando é pausa, não é tão longa quanto a pausa de fim de verso, nem tão pequena que não se perceba como pausa. O andamento datílico dá unidade a todo verso, impedindo que ele seja apenas uma justaposição (assinarteto) daqueles metros portugueses. A correta leitura tem assim resultado extraordinário porque, sempre soando como hexâmetros datílicos (uma tônica seguida de duas átonas), que são estranhos à métrica tradicional portuguesa, os versos, cindidos, não deixam de ter ritmo muito conhecido para nós, lusófonos. Assim, o alheio, o estranho (bem a calhar num texto estrangeiro! $)^{16}$, inocula-se no que é costumeiro e produz como que uma dissonância sedutora entre algo familiar e uma coisa diferente: isso não é "prosa ritmada”, isto não é prosaísmo. Aliás, é uma virtude segundo um critério, formulado por Rudoph Pannwitz, que o próprio Campos, traduzindo-o, tanto proclamou:

Nossas versões, mesmo as melhores, partem de um princípio falso. Pretendem germanizar o sânscrito, o grego, o inglês, em lugar de sanscritizar o alemão, grecizá-lo, anglizá-lo. Têm muito maior respeito pelos usos de sua própria língua do que pelo espírito da obra estrangeira [...] $\mathrm{O}$ erro fundamental do tradutor é fixar-se no estágio em que, por acaso, se encontra sua língua, em lugar de

16 Diz Rudolph Pannwitz (p. 200; tive acesso só à versão em inglês porque, como se verá a seguir, foi a usada e celebrizada por Haroldo de Campos; a ausência de pontuação e de minúsculas é do original): “'awkwardness' here is almost always more a virtue than a vice and whoever is capable of accomplishing anything at all will achieve mastery only through strictly imitating the original form by every means and by transcending every means thus receiving it more internally and more authentically as a re-creator". 
submetê-la ao impulso violento que vem da língua estrangeira ${ }^{17}$.

Ora, se isso vale para a língua, sintaxe, morfologia, melopeia, fanopeia, logopeia etc, por que não valeria para o metro, que não é menos substancial do que elas no poema? Muitos tradutores de poesia antiga, como o próprio Haroldo de Campos, ou como vários de nós, traduziram o hexâmetro pelo decassílabo ou pelo dodecassílabo, que são metros convencionais, e assim procedendo, aportuguesaram metricamente o latim e o grego. Mas ao contrário, os tradutores hexamétricos - estrangeiros ou lusófonos, antigos ou contemporâneos - e entre eles Carlos Alberto Nunes, ao traduzir a épica como fizeram, lograram helenizar ou latinizar metricamente o português, como de certa maneira queriam Pannwitz e Campos. As traduções hexamétricas de Nunes, como todas, hão de ter defeitos, mas devem ser conhecidas e avaliadas pelo que, mediante crítica ponderada e erudita, se argumentar e demonstrar como defeitos, em meio aos quais hão também de revelar-se não poucas qualidades. Devem, sobretudo, ser criticadas primeiro pelo que positivamente possuam, pelo que o tradutor estabeleceu como princípio, e não pelo que o crítico acha que faria no seu lugar.

\section{O REPTO DE Nunes nUm POEMA ORIGINAL: CASSIANo Ricardo}

No mesmo artigo de 1992, Haroldo de Campos puxando pela memória ("se bem me lembro") afirma que Mário Faustino louvara a solução de buscar no verso de 16 sílabas o equivalente vernáculo do hexâmetro. Não foi assim, infelizmente, já que não teria sido pouco uma opinião de Mário Faustino favorável ao metro. Todavia, Faustino talvez tenha feito mais, porque, escrevendo no Suplemento Dominical do Jornal do Brasil (RJ) em 7 de abril de $1957^{18}$, fazia crítica ao lançamento das Poesias completas de Cassiano Ricardo. A certa altura, põe sérios reparos, é verdade, no poema "Eu no barco de Ulisses", dizendo:

17 Campos, p. 144. O texto em inglês é o seguinte: "6. our translations even the best proceed from a false principle they want to germanize hindi greek english instead of hindiizing grecizing anglicizing german. they have a much more significant respect for the usages of their own language than for the spirit of the foreign work. [...]. 7. the fundamental error of the translator is that he maintains the accidental state of his own language instead of letting it violently moved by the foreign language". (PANNWITZ, p. 198 e 199).

18 Com o título "Vítor Hugo brasileiro", a resenha foi republicada no livro Mário Faustino: de Anchieta aos Concretos, organizado por Maria Eugênia Boaventura. 
O mesmo não se pode dizer de "Eu no barco de Ulisses"19. A ideia central, emprestada dos Cantos, de Ezra Pound (aproveitar, modernamente, o Canto XI da Odisseia), a versificação emprestada de Carlos Alberto Nunes (tradução, ritmicamente conforme ao original grego, da Ilíada e da Odisseia)... excesso de meios e deficiência de resultados.

Todavia reconhece já não só as traduções de Nunes positivamente como fato poético, senão também a peculiar versificação. Nunes não ter inventado essa versificação em português importa menos aqui do que ter sido ela, ou melhor, o uso que Nunes, traduzindo, dela fez, um dos meios pelos quais Cassiano Ricardo pôde compor um poema original, revisitando a antiga matéria homérica. Independentemente da qualidade do poema, a revisitação ganha ainda maior significado, digamos assim, porque ecoa o hexâmetro antigo. Em outras palavras, para que Cassiano Ricardo produzisse o desejado efeito alusivo, por assim dizer "paraépico", efeito que, enfim, é intertextual, alçou as traduções de Nunes, por causa do metro, à condição de referência para produzir em português o efeito de épica que pretendia naquele poema, isto é, ele transformou a Ilíada e a Odisseia de Nunes em hipotexto do qual seu poema é o hipertexto ${ }^{20}$. Nem mesmo por ser rara a experiência de Cassiano Ricardo, nem sequer pelo fracasso, se concordarmos com Faustino, ela deixa de ter significância poética, quer pela autoridade de quem Cassiano Ricardo emulava, Ezra Pound (que é um fato da história da poesia brasileira), quer pela importância primacial que uma tradução ganha para a composição de um poema original (que é fato da história da tradução de poesia antiga em português no Brasil): como poema original em português, "Eu no Barco de Ulisses", para ter ressonância épica na língua em que foi composto, requeria já não só para o poeta, mas já para os leitores, uma caixa de ressonância épica em nossa língua, se me é permitido assim dizer, aparato esse que só pôde ser dado pelas únicas traduções hexamétricas integrais da épica homérica existentes ainda hoje em português, que são as de Carlos Alberto Nunes.

19 Faustino refere-se ao êxito poético do poema "Musa paradisíaca", que universaliza uma experiência nacional, retificando o período verde-amarelo.

20 Operação análoga, porém ainda em tradução, realizou Leandro Dorval Cardoso ao verter os versos 219-245 do Anfitrião, de Plauto. Embora composta em créticos, o tradutor, mercê do caráter épico que essa passagem paródica tem (Sósia narra a batalha contra os teléboas, que supostamente presenciara), traduziu-a em hexâmetros datílicos à maneira de Nunes. Assim fazendo, empresta ao passo elocução épica que a paródia, para rebaixá-la, necessita. 


\section{A linhagem DE TRAdUTORES HEXAmÉtRicos (CONTINUAÇÃo)}

Restringindo-me só ao que foi publicado e considerando a data de publicação, é mister registrar:

8. Rodrigo Tadeu Gonçalves, que liderou dez estudantes para traduzir coletivamente excerto das Metamorfoses (Canto X, v. 1-297), de Ovídio, servindo-se do hexâmetro de Nunes, ampliando o emprego de certos tropos, em particular, a anacruse.

9. Leonardo Antunes, que utilizou mais rigidamente o metro para verter os hexâmetros da elegia arcaica grega ${ }^{21}$, mas com engenho criou por variação um interessante pentâmetro vernáculo para verter os respectivos pentâmetros gregos.

10. Érico Nogueira, que, um pouco mais distante da regularidade do verso de Nunes, mas sob o inegável repto dele, empregou um verso de seis sílabas tônicas, a que chama "hexatônico", para traduzir os idílios hexamétricos de Teócrito de Siracusa.

\section{CONCLUSÃo: UMA DÍVIDA A PAGAR, UMA HISTÓRIA POR FAZER}

No Brasil e, até onde sabemos, também em Portugal, os tradutores de poesia e prosa grega e latina (digo mais, os poetas tradutores de textos antigos) não apenas são egressos da Universidade, mas pertencem à Universidade, como professores e pesquisadores, que são potenciais docentes. Portanto, já não lhes cabem, já não nos cabem, com o devido respeito, nem o silêncio que aniquila - aquele que presume e talvez deseje que uma tradução não exista - nem o discurso que não a alcança porque não se põe à altura dela. Se nos meios literários, se na imprensa, se no meio editorial a discordância quanto a uma teoria divergente da tradução, da qual o hexâmetro de Carlos Alberto Nunes é só um exemplo, ou se o dissenso quanto a uma estratégia diversa ou se simplesmente a diferença de gosto podem justificar vaidoso e privado desinteresse, creio que a Universidade não pode dar-se ao luxo de não se interessar pelas traduções antigas e recentes feitas em português, muito menos quando ainda têm muitos leitores em toda sociedade, como são as de Carlos Alberto Nunes, e não praticamente só nos grupos acadêmicos da própria Universidade. Já não é questão de crítica, nem de gosto, mas de ofício. 


\section{REFERÊNCIAS}

Poemas de Carlos Alberto Nunes

NUNES, Carlos Alberto. Adamastor ou o naufrágio de Sepúlveda: comédia em três atos e um prólogo. São Paulo, Edições da Academia Paulista de Letras, 1972.

. Beckmann ou a tragédia do general Gomes Freire de Andrade em cinco atos e um prólogo. São Pauilo: Edições da Academia Paulista de Letras,1975.

. Estácio. Drama. Precedido de um "Ensaio sobre a natureza do drama”. São Paulo, Melhoramentos, 1971.

. Moema. Drama. São Paulo: Atena Editora, 1950.

Os Brasileidas. Epopeia nacional. Precedida de um "Ensaio sobre a poesia épica". São Paulo: Melhoramentos, 1962.

2. Traduções de Carlos Alberto Nunes

GENTA, Edgardo Ubaldo. A Amazônia: tragiepopéia em 4 jornadas. Tradução de: NUNES, C. A. Prefácio de Arthur Cézar Ferreira Reis. Rio de Janeiro: Editora Artenova, 1968.

GOETHE, Johann Wolfgang von. Estela. Tragédia. Tradução de: NUNES, C. A. São Paulo: Edições Melhoramentos, 1949.

.Iphigenie auf Tauris. Eein Schauspiel. Ifigênia em Táuride. Drama. Tradução de: NUNES, C. A. São Paulo: Instituto Hans Staden, 1964.

HEBBEL, Friedrich. Tragédias: Judite. Giges e seu anel. Os nibelungos. Tradução de: NUNES, C. A. São Paulo: Melhoramentos, 1964.

HOMERO. Ilíada. 5. ed. Tradução em versos de: NUNES, C. A. Rio de Janeiro: Ediouro, 2005. Passagens citadas foram conferidas com a edição da Ediouro/Tecnoprint, Rio de Janeiro, 198?, Coleção Universidade, e com a da Atena Editora, de São Paulo, de 1941.

. Odisseia. 6. ed. Tradução de: NUNES, C. A. Rio de Janeiro: Ediouro, 2004. Passagens citadas foram conferidas com a edição da Ediouro/Tecnoprint, Rio de Janeiro, 198?, Coleção Universidade, e com a da Atena Editora, de São Paulo, de 194?.

VIRGÍlIO. Eneida. $1^{\text {a }}$ edição bilíngue. Tradução de: NUNES, C. A. Organização, apresentação e notas de João Angelo Oliva Neto. São Paulo: Editora 34, 2014.

3. Métrica, poesia, tradução.

BERNHARDT-KABISCH, Ernest. 'When Klopstock England defied': Coleridge, Southey, and the German/English hexameter. Comparative literature, Spring, v. 55, n. 2, p. 130-163. 2003.

CÂMARA JR., Joaquim Mattoso. Machado de Assis e o "Corvo" de Edgar Allan Poe. Revista do Livro III, Rio de Janeiro: Instituto Nacional do Livro, v.11, p.101-109, set. 1958.

CAMPOS, Haroldo de. Para transcriar a "Ilíada". Revista USP, São Paulo, v.12, p.143-161, dez./ jan./fev. 1991-2.

CARDOSO, Leandro Dorval. A vez do verso: estudo e tradução do Amphitruo, de Plauto. Dissertação (Mestrado em Letras) - Setor de Ciências Humanas, Letras e Artes, Universidade Federal do Paraná, Curitiba, 2012, inédita. p. 97, 140 e 141. Orientada por Rodrigo Tadeu Gonçalves.

CARDUCCI, Giosuè. La poesia barbara nei secoli XV e XVI. Bologna: Nicola Zanichelli, Libraio, Editore, Tipografo, 1881.

CONTO, Luana de. Carlos Alberto Nunes, tradutor dos clássicos. In: SEMANA ESTUDOS CLÁSSICOS, 23, 2008, Araraquara. Anais... p. 60-67. 
FAUSTINO, Mário. Vitor Hugo brasileiro. In: BOAVENTURA, M. E. (Org.), Mário Faustino: de Anchieta aos Concretos. São Paulo: Companhia das Letras, 2003. p. 186-202.

GONÇALVES, Rodrigo Tadeu et al. (Coord.). Uma tradução coletiva das Metamorfoses 10.1-297 com versos hexamétricos de Carlos Alberto Nunes. Scientia Traductionis, v.10, p.110-32, 2011.

LEMOS, Fernando. Fernando Pessoa e a nova métrica. Transcrição e estudo de manuscrito inédito: a imitação de formas e metros líricos greco-romanos em Ricardo Reis. Lisboa: Inquérito, 1993.

NOGUEIRA, Érico. Verdade, contenda e poesia nos idílios de Teócrito. São Paulo: Humanitas, 2013.

OLIVA NETO, João Angelo. A Eneida em bom português: considerações sobre teoria e prática da tradução poética. In: DOS SANTOS, M. et al (orgs.). II Simpósio de Estudos Clássicos. São Paulo: Humanitas, 2007, p. 65-88.

OLIVA NETO, João Angelo; NOGUEIRA, Érico. O hexâmetro datílico vernáculo antes de Carlos Alberto Nunes. Scientia Traductionis, Florianópolis, v. 13, p. 295-311, 2013. Disponível em: < https://periodicos.ufsc.br/index.php/scientia/index >. Acesso em: 29 jul. 2014.

PANNWITZ. Rudolph. The shock of the foreigner. Translated by: DWELL, W. S. Delos, Austin: National Tranlation Center, v. 4, p. 198-201, 1970.

PASCOLI, Giovanni. Regole di metrica neoclassica. In: secondo. Milano: Arnoldo Mondadori Editore, 2002. . Poesie e prose scelte. Tomo

PEJENAUOTE, Francisco. La adaptación de los metros clásicos en castellano. Estudios Clásicos, v.63, p. 213-34, 1971.

RICARDO, Cassiano. Eu no barco de Ulisses (rapsódia, em 10 fragmentos). In: RICARDO, Cassiano. Melhores poemas. Seleção de Luiza Franco Moreira. São Paulo: Global, 2003. p. 141-161. . Poesias completas. Rio de Janeiro: Livraria José Olympio, Editora, 1957.

TÁPIA, Marcelo. Diferentes percursos de tradução da épica homérica como paradigmas metodológicos de recriação poética: um estudo propositivo sobre linguagem, poesia e tradução. Tese (Doutorado em Teoria Literária e Literatura Comparada) - Faculdade de Filosofia, Letras e Ciências Humanas, Universidade de São Paulo, 2014, inédita. Orientada por Aurora Fornoni Bernardini.

TEIXEIRA, Ivan (org.). Multiclássicos épicos: Prosopopeia. O Uraguai. Caramuru. Vila Rica. A confederação dos tamoios. I-Juca Pirama. São Paulo: Edusp / Imprensa Oficial do Estado, 2008.

Submetido em: 28/02/2014

Aceito em: 09/05/2014 